\title{
Morphine-Induced Chemotaxis and Brain-Derived Neurotrophic Factor Expression in Microglia
}

\author{
Naoko Takayama and Hiroshi Ueda \\ Division of Molecular Pharmacology and Neuroscience, Nagasaki University Graduate School of Biomedical Sciences, Nagasaki 852-8521, Japan
}

The addition of morphine at $1 \mu \mathrm{m}$ induced morphological changes of cultured microglia such that they changed from having globular or bipolar rod-like shapes to being flat and lamellipodial, with membrane ruffling at the edge, which was stained with phalloidin. The membrane ruffling was clearly colocalized with Rac. Morphine also induced chemotaxis in Boyden chamber analysis at concentrations of $1 \mu \mathrm{M}$ or more in microglia and the microglial cell line EOC 2 . All of these changes were abolishable by naloxone, antisense oligodeoxynucleotide for $\mu$-opioid receptor (MOR), pertussis toxin (PTx), and wortmannin, but not genistein or 1,10-phenanthroline. The addition of morphine to microglia stimulated the gene expression of brain-derived neurotrophic factor (BDNF) as early as the $1 \mathrm{hr}$ point, and this lasted for $>12 \mathrm{hr}$. Morphine induced BDNF gene expression and ERK1/2 (extracellular signal-regulated kinase 1/2) phosphorylation, and these were abolishable by naloxone, wortmannin, PD98059, genistein, and 1,10-phenanthroline. The addition of conditioned medium derived from the culture of morphine-treated microglia also increased the phosphorylation of ERK1/2. All of these findings suggest that morphine induces significant changes in both morphology and gene expression at relatively high concentrations, but the underlying signaling pathways downstream of MOR and $\mathrm{G}_{\mathrm{i} / \mathrm{o}}$ appear to be different from each other. Phosphoinositide 3-kinase $\gamma$ activation and Rac activation are involved in chemotaxis, whereas indirect pathways through ERK1/2 phosphorylation induced by unknown growth factors generated through an MOR-mediated metalloprotease activation are linked to the enhanced BDNF gene expression.

Key words: membrane ruffling; Rac; EOC 2; phosphoinositide 3-kinase $\gamma$; PI3K $\gamma$; metalloprotease; transactivation

\section{Introduction}

Accumulating evidence suggests that glial cells, such as astrocytes, oligodendrocytes, and microglia, influence various neuronal activities, including neuronal transmission and survival, through the activity of cytokines and neurotrophins (Fields and StevensGraham, 2002; Hansson and Ronnback, 2003). Cytokines and neurotrophins are substances known to effect both morphological and functional changes in neurons such as enhancing survival and inducing differentiation. More recent findings indicate that neurotrophins may also act as synaptic modulators (Poo, 2001). Such interactions have been suggested to be further augmented by microglial chemotaxis and the altered expression of the glutamate transporters of astrocytes (Fields and Stevens-Graham, 2002). Recent studies suggest that neuronal plasticity is regulated by mutual interactions performed by and through a variety of mediators released among neurons and glial cells (Cotrina et al., 2000; Fields and Stevens-Graham, 2000).

In addition to the neuronal plasticity related to behavioral activities such as memory and learning, drug-induced plasticity

Received Aug. 3, 2004; revised Nov. 18, 2004; accepted Nov. 23, 2004.

We appreciate the review of the manuscript before submission by Pacific Edit. We thank Dr. C. J. Evans (Department of Phychiatry and Biobehavioral Sciences, University of California, Los Angeles, CA) for the gift of rabbit anti-MOR1 antiserum.

Correspondence should be addressed to Dr. Hiroshi Ueda, Division of Molecular Pharmacology and Neuroscience, Nagasaki University Graduate School of Biomedical Sciences, 1-14 Bunkyo-machi, Nagasaki 852-8521, Japan. Email: ueda@net.nagasaki-u.ac.jp.

DOI:10.1523/JNEUROSCI.3170-04.2005

Copyright $\odot 2005$ Society for Neuroscience $\quad$ 0270-6474/05/250430-06\$15.00/0 has attracted the interest and concern of neuroscientists. A representative instance is the morphine tolerance and dependence that develop during chronic treatment, which has been long discussed from the point of view of in vivo studies (Ueda et al., 2000; Williams et al., 2001; Inoue et al., 2003). Current work suggests that opioid tolerance and dependence may be usefully considered in terms of "anti-opioid" systems, including glutamatergic neurons via the NMDA receptor as well as nociception neurons (Ueda et al., 2003). The relevant mechanisms may include synaptogenesis and enhanced receptor expression in neurons. Such drug-induced plasticity may also be fortified by the activity of glial cells. Chronic morphine treatments induce the activation of astrocytes in vivo (Song and Zhao, 2001; Raghavendra et al., 2002). Chronic morphine treatments downregulate the neuronal and astrocyte glutamate transporters (Mao et al., 2002), which leads to an enhancement of synaptic glutamate or an increase in the anti-opioid level. These treatments also activate microglia (Song and Zhao, 2001) and release cytokines to promote the release of glutamate from neurons (Bal-Price and Brown, 2001). Thus, it is evident that chronic morphine exerts significant effects on neuronal plasticity through glial activity. Indeed, it is known that astrocytes and microglia express $\mu-, \delta$-, and $\kappa$-opioid receptors as well as neurons express them (Ruzicka et al., 1995; Calvo et al., 2000). However, direct evidence for morphine-induced activation of microglia has yet to be obtained. Here, we report morphine-induced morphological changes in microglia, along with their genetic regulation and signaling mechanisms. 


\section{Materials and Methods}

Microglial culture. Mixed glial culture was prepared from the whole-brain tissues of 17-d-old embryonic Wistar rats (Hamabe et al., 2003) and maintained for 10-14 d in DMEM with 10\% fetal bovine serum (FBS). The purity of microglia obtained as floating cells over the mixed glial culture was $98-100 \%$, as determined by immunostaining with an OX-42 antibody (BD Biosciences PharMingen, San Jose, CA).

Cell line culture. Mouse microglial EOC 2 cells (American Type Culture Collection, Manassas, VA) were grown in 70\% DMEM containing $4.5 \mathrm{gm} / \mathrm{l}$ glucose, $10 \% \mathrm{FBS}$, and 20\% LADMAC-conditioned media produced from the LADMAC cell line (American Type Culture Collection), which secretes CSF-1 (colony-stimulating factor-1) (Olivas et al., 1995).

Membrane ruffling. Microglial cells at a density of $2 \times 10^{4}$ cells $/ \mathrm{cm}^{2}$ were introduced into eight wells of a poly-L-lysine-coated Lab-Tek chamber (Nunc, Roskilde, Denmark), washed three times with serum-free DMEM, starved for $30 \mathrm{~min}$ in the same medium, and then stimulated with DMEM or morphine/ $\mathrm{HCl}$ (Takeda Chemical Industries, Osaka, Japan) at $1 \mu \mathrm{M}$ for $30 \mathrm{~min}$ at $37^{\circ} \mathrm{C}$ in a $5 \% \mathrm{CO}_{2}$ atmosphere. After fixation with PBS containing $4 \%$ paraformaldehyde (PFA) for $30 \mathrm{~min}$ at $25^{\circ} \mathrm{C}$, microglia were permeabilized using PBS containing $0.2 \%$ Triton X-100 for $5 \mathrm{~min}$ and incubated in a blocking buffer containing $1 \%$ bovine serum albumin and Texas Red-conjugated phalloidin (Texas Red-X Phalloidin, $5 \mathrm{U} / \mathrm{ml}$; Molecular Probes, Eugene, OR) for $20 \mathrm{~min}$ at $25^{\circ} \mathrm{C}$. Immunolabeled cells were mounted with PermaFluor (Thermo Electron Corporation, Pittsburgh, PA), and imaged on an AxioVision 3.0 (Zeiss, Tokyo, Japan) attached to a fluorescence microscope (BX50; Olympus Optical, Tokyo, Japan).

Rac translocation. Fixed cells were incubated overnight at $4^{\circ} \mathrm{C}$ with rabbit polyclonal antibody against Rac (1:200; Santa Cruz Biotechnology, Santa Cruz, CA) and then with FITC-conjugated anti-rabbit IgG (1:100; Cappel, Aurora, OH) for $2 \mathrm{hr}$. F-actin was costained with Texas Red-conjugated phalloidin (Honda et al., 2001).

Chemotaxis assay using the Boyden Chamber. Chemotaxis of microglia using the Boyden Chamber (Neuroprobe, Bethesda, MD) was assessed, as reported previously (Yokomizo et al., 1997). Polycarbonate filters with 5 $\mu \mathrm{m}$ pores (Neuroprobe) were coated with $10 \mu \mathrm{g} / \mathrm{ml}$ bovine plasma fibronectin (Invitrogen, Carlsbad, CA) for $2 \mathrm{hr}$. A dry-coated filter was installed in the Boyden Chamber placed on a 24-well plate, the bottom wells of which were filled with serum-free DMEM containing morphine (200 $\mu \mathrm{l})$. Freshly prepared microglia were suspended in serum-free DMEM, and the cell suspension was placed into the top wells $\left(100 \mu \mathrm{l}, 2 \times 10^{4}\right.$ cells per well). After incubation at $37^{\circ} \mathrm{C}$ for $90 \mathrm{~min}$, cells on the filter were washed once with serum-free DMEM, and the filter was disassembled. The cells were fixed with 4\% PFA in PBS and stained with $10 \mu \mathrm{g} / \mathrm{ml}$ Hoechst 33342 (Molecular Probes, Eugene, $\mathrm{OR}$ ) at $37^{\circ} \mathrm{C}$ for $15 \mathrm{~min}$, and the filters were removed and mounted with PermaFluor. The number of cells that migrated to the bottom side was measured with an NIH Image analyzer.

Treatments with antisense oligodeoxynucleotide. The culture media with $20 \mu \mathrm{m}$ antisense oligodeoxynucleotide (AS-ODN) (5'-GCC GGC GCT GCT GTC CAT-3'), its missense oligodeoxynucleotide (MS-ODN) (5'-GCC GGC GGT GCT GCT CAT-3') for the $\mu$-opioid receptor (MOR) (Sawady, Tokyo, Japan) at $20 \mu \mathrm{M}$, or vehicle were changed twice per day for $3 \mathrm{~d}$. On the third day, EOC 2 cells were harvested in serumfree medium and used for the chemotaxis assay.

Western blot analysis. SDS-PAGE with $12 \%$ polyacrylamide gel, immunoblot analysis, and visualization were performed using proteins $(20$ $\mu \mathrm{g})$, rabbit anti-MOR1 antiserum (1:500) in 1\% bovine serum albumin, rabbit anti-phospho-ERK1/2 (extracellular signal-regulated kinase 1/2) (1:1000) or rabbit anti-ERK1/2 (1:1000; New England Biolabs, Tokyo, Japan), and SuperSignal West Pico chemiluminescent substrate (Pierce, Rockford, IL) for the detection of horseradish peroxidase (Hamabe et al., 2003).

Quantitative real-time PCR. Microglia at a density of $2 \times 10^{4} \mathrm{cells} / \mathrm{cm}^{2}$ in DMEM with $10 \%$ FBS were washed twice with DMEM with $1 \%$ FBS and stimulated with $1 \mu \mathrm{M}$ morphine (1\% FBS/DMEM) for 1, 3, 6, and 12 hr. Total RNA $(1 \mu \mathrm{g})$ prepared from such treated microglia by means of TRIzol (Invitrogen) was used for cDNA synthesis with Superscript II reverse transcriptase and random hexamer primers (Invitrogen). Real- time quantitative PCR was performed using an ABI Prism 7000 Sequence Detection system (Applied Biosystems, Tokyo, Japan), using qPCR Mastermix for SYBR ${ }^{\mathrm{R}}$ Green I (Eurogentec, Seraing, Belgium) containing dNTPs(+dUTP), Hot Goldstar DNA polymerase, and Urasil-N Glycosilase, according to the directions of the manufacturer. The cycling conditions for all primers were the following: hold for $10 \mathrm{~min}$ at $95^{\circ} \mathrm{C}$ to activate the Hot Goldstar DNA polymerase, followed by 50 cycles consisting of two steps, $15 \mathrm{sec}$ at $95^{\circ} \mathrm{C}$ (denaturing) and $1 \mathrm{~min}$ at $60^{\circ} \mathrm{C}$ (annealing-extension). The brain-derived neurotrophic factor (BDNF) mRNA levels were evaluated by the use of two different sets of primers and normalizing genes, such as glyceraldehyde-3-phosphate dehydrogenase (GAPDH) and $\beta$-actin (ACTB). In all cases, the validity of amplification was confirmed by the presence of a single peak in the melting temperature analysis and linear amplification against the PCR cycle.

Statistical analysis. The data were analyzed using Student's $t$ test after multiple comparisons of ANOVA. The criterion of significance was set at ${ }^{\star} p<0.05$. All results are expressed as the mean \pm SEM.

\section{Results}

\section{Morphine-induced membrane ruffling and Rac activation in microglia}

Microglia harvested from culture bottles exhibited a small, spherical shape just after seeding in DMEM with 10\% FBS. Several minutes later, however, they firmly attached to the dish and changed so as to become spread, flat, and amoeboid-like within $30 \mathrm{~min}$. These cells gradually shrank and then became globular or bipolar rod-like in shape by $12 \mathrm{hr}$ after the seeding. As mentioned in Materials and Methods, microglia were washed three times with serum-free DMEM 12 hr after the seeding and starved for 30 min in the same medium. Further incubation with morphine ( 1 $\mu \mathrm{M})$ changed the cell shape of the microglia to become amoeboid-like and enlarged to $\sim 50 \mu \mathrm{m}$ in diameter within 30 min. The cells were fixed $30 \mathrm{~min}$ after the morphine addition and stained with Texas-Red-conjugated phalloidin. As seen in Figure $1 \mathrm{Ab}$, phalloidin-stained membrane ruffling is observable at the edge of the cell.

Morphine-induced membrane ruffling was abolished by 30 min pretreatment with naloxone $(1 \mu \mathrm{M}), 12 \mathrm{hr}$ pretreatment with pertussis toxin $(\mathrm{PTx})(100 \mathrm{ng} / \mathrm{ml})$, or $30 \mathrm{~min}$ pretreatment with wortmannin $(1 \mu \mathrm{M})$, a phosphoinositide 3-kinase (PI3K) inhibitor (Fig. $1 A d, A f, A h)$, although these inhibitors themselves exerted no effect on the control morphology (Fig. $1 A c, A e, A g$ ). The morphine-induced ruffling was not affected by genistein $(3 \mu \mathrm{M})$, a tyrosine kinase inhibitor, or 1,10-phenanthroline $(300 \mu \mathrm{M})$, a metalloprotease inhibitor (data not shown). The intense phalloidin staining showing the membrane ruffling was further stained with anti-Rac 1 IgG (Fig. $1 B$ ).

\section{Morphine-induced chemotaxis of microglia in the Boyden Chamber}

Chemotactic motility closely related to membrane ruffling was determined by the penetration of cells through a polycarbonate membrane filter of a Boyden Chamber 90 min after the start of the experiments. As shown in Figure 2, $A$ and $B$, morphine significantly increased concentration-dependent chemotaxis, and this was abolished by pretreatment with naloxone, PTx, or wortmannin, although these inhibitors had no effect on the control chemotactic motility (Fig. 2C).

\section{Blockade of morphine-induced chemotaxis in EOC 2 cells by MOR antisense treatment}

A longer treatment of microglia with AS-ODN requires a monolayer of astrocytes, which also express opioid receptors. Because these opioid receptors in astrocytes might also be affected by 
morphine, the evaluation of AS-ODN effects under this scenario would be complicated. Thus, we used a microglial cell line, EOC 2 cells, which do not require an astrocyte feeder layer. As shown in Figure 3, A and $B$, morphine induced both membrane ruffling and chemotaxis, and the chemotaxis was completely abolished by AS-ODN for MOR, which significantly reduced MOR-immunoreactive signals. However, the MS-ODN treatment had no effect.

\section{Morphine stimulates BDNF}

gene expression

BDNF mRNA expression was enhanced as early as $1 \mathrm{hr}$ after the addition of $1 \mu \mathrm{M}$ morphine, and the level remained constant for at least $12 \mathrm{hr}$ when evaluated by the use of different normalizing genes (GAPDH and $\mathrm{ACTB}$ ) or different sets of primers for $\mathrm{BDNF}$ gene (Fig. 4Aa). Morphine concentration dependently increased BDNF gene expression at the time point of $1 \mathrm{hr}$ (Fig. $4 A b$ ).

This enhanced BDNF gene expression was blocked by naloxone, wortmannin, the MEK (mitogen-activated protein kinase kinase) inhibitor PD98059 (1 $\mu \mathrm{M})$, genistein $(3 \mu \mathrm{M})$, and 1,10-phenanthroline (300 $\mu \mathrm{M})$, but not by the phospholipase $\mathrm{C}$ inhibitor U73122 $(1 \mu \mathrm{M})$, the SAPK (stress-activated protein kinase) SP600125 (1 $\mu \mathrm{M})$, a JNK (cJun $\mathrm{N}$-terminal protein kinase) inhibitor, or the EGFR (epidermal growth factor receptor) tyrosine kinase inhibitor AG1478 (3 $\mu \mathrm{M})$, as shown in Figure $4 A c$.

As shown in Figure $4 B a$, morphine significantly stimulated the phosphorylation of ERK $1 / 2$ only at $30 \mathrm{~min}$. This phosphorylation was inhibited by naloxone, wortmannin, PD98059, genistein, and 1,10phenanthroline (Fig. $4 B b$ ), although these inhibitors had no effects on the control phosphorylation. The conditioned medium $(\mathrm{CM})(100 \%)$ prepared from the morphine-stimulated culture also stimulated the phosphorylation of ERK1/2 at 30 $\mathrm{min}$ in the presence of naloxone. On the other hand, the phosphorylated JNK/ SAPK level remained unchanged at any of the time points of $5,15,30$, or $60 \mathrm{~min}$ after the addition of morphine (data not shown).

\section{Discussion}

The present study provides evidence that morphine induces morphological changes in cultured microglia from a ramified to an amoeboid shape. The specific changes observed include membrane ruffling and chemotaxis. Because membrane ruffling is found at the front edge of migrating cells as early as $10 \mathrm{~min}$ after morphine addition, it is believed to be a driving force in chemotaxis (Lauffenburger and Horwitz, 1996). Indeed, the pharmacological mechanisms through $\mathrm{G}_{\mathrm{i} / \mathrm{o}}$-coupled MOR and PI3K are quite similar for both mechanisms and consistent with the accu-
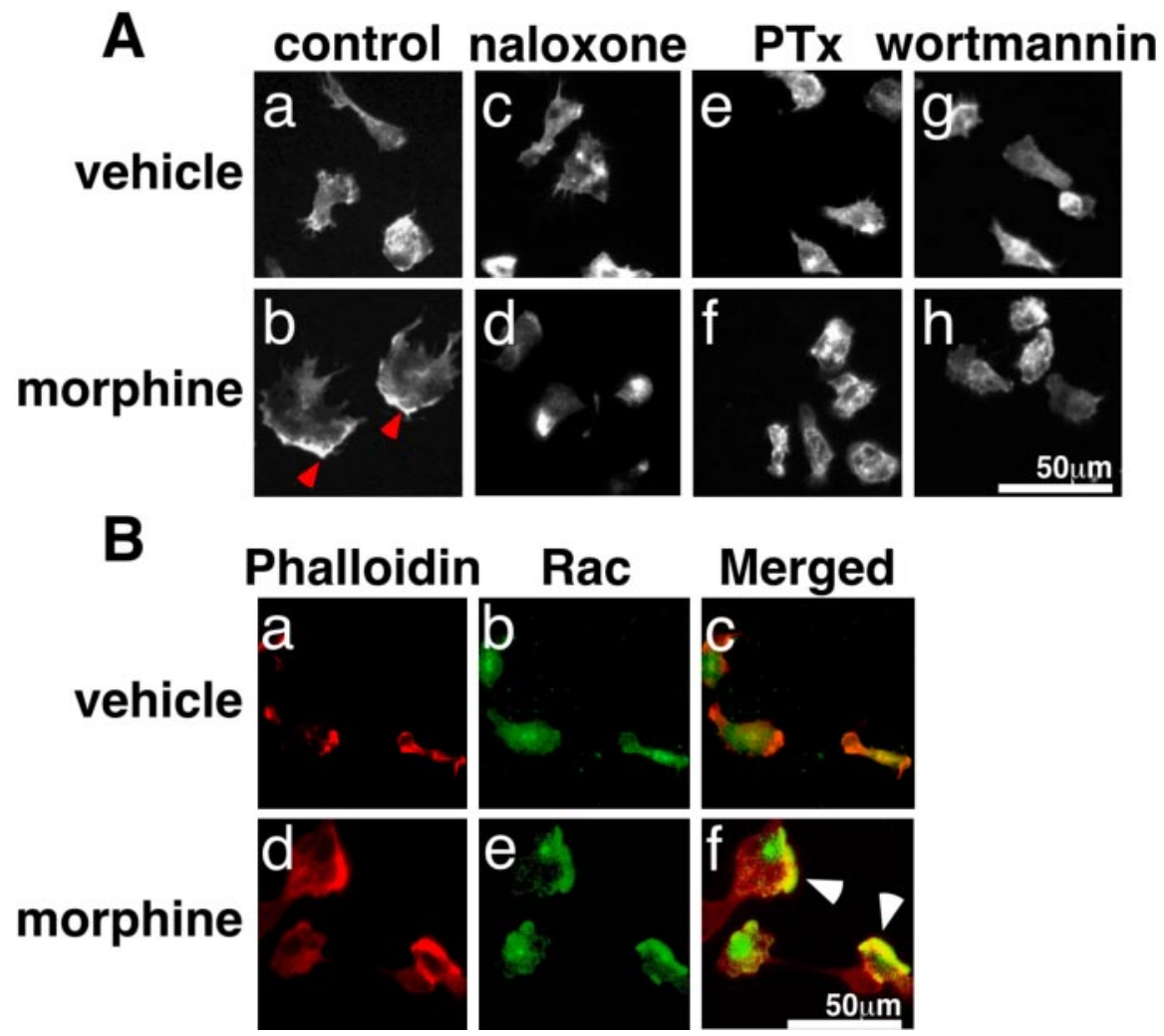

Figure 1. Morphine-induced membrane ruffling and Rac activation in microglia. $A$, Effects of inhibitors on morphine-induced membrane ruffling. Microglia were stimulated with DMEM $(a, c, e, g)$ or $1 \mu \mathrm{M}$ morphine $(b, d, f, h)$ for 30 min after $12 \mathrm{hr}$ of pretreatment with $100 \mathrm{ng} / \mathrm{ml} \mathrm{PTx}(e, f), 30$ min of pretreatment with $1 \mu \mathrm{m}$ naloxone $(c, d)$, and $1 \mu \mathrm{m}$ wortmannin $(g, h) . B$, Translocation of Rac. The cells were stimulated with DMEM $(a-c)$ or $1 \mu \mathrm{m}$ morphine $(d-f)$ for $30 \mathrm{~min}$ and stained with Texas Red-conjugated phalloidin $(a, d)$ and Rac antibody and FITC-conjugated anti-rabbit $\lg G(b, e)$. Merged photographs show the colocalization of Rac and F-actin in the ruffling region $(c, f)$, as indicated by the arrowheads. Scale bars, $50 \mu \mathrm{m}$.

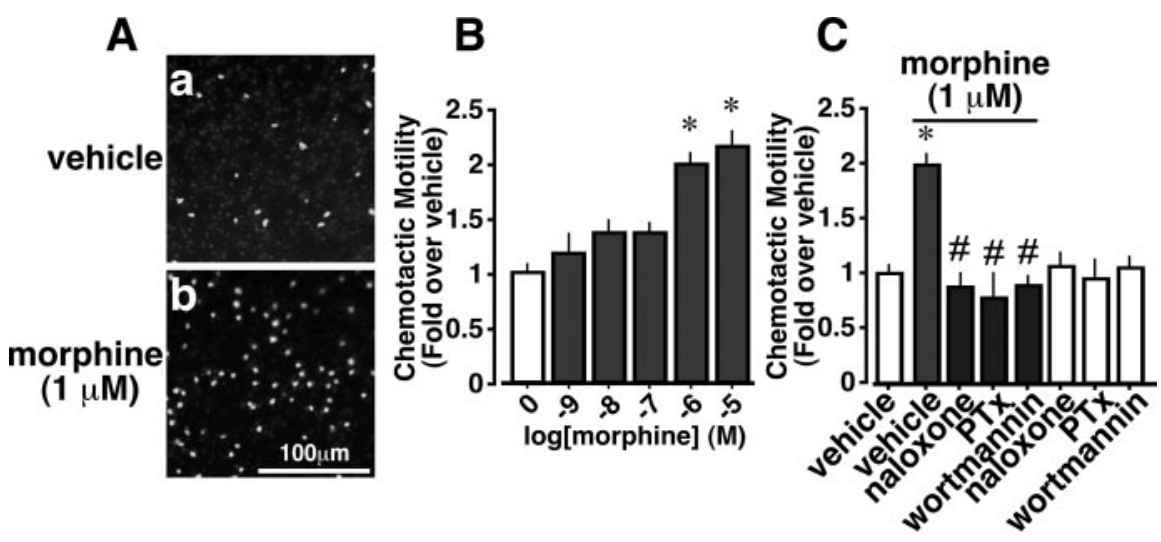

Figure 2. Morphine-induced chemotaxis of microglia in the Boyden Chamber. Microglia were stimulated with DMEM or $1 \mu \mathrm{M}$ morphine for 90 min after $12 \mathrm{hr}$ of pretreatment with $100 \mathrm{ng} / \mathrm{ml} \mathrm{PTx}$, or 30 min of pretreatment with $1 \mu \mathrm{m}$ naloxone and $1 \mu \mathrm{m}$ wortmannin. The ratio of filter-penetrated cells that migrated to the morphine stained by Hoechst 33342 to the control (DMEM) was evaluated as chemotaxis. $A$, Light microscopic observation of migrated cells. $B$, Concentration dependency of morphineinduced chemotaxis. C, Effects of inhibitors on morphine-induced chemotaxis. Results are expressed as the mean \pm SEM from three independent experiments. ${ }^{*} p<0.05$ versus vehicle; ${ }^{\sharp} p<0.05$ versus morphine alone. mulating findings that have suggested that chemotaxis is mediated by non-chemokine $\mathrm{G}_{\mathrm{i} / \mathrm{o}}$-coupled receptors and requires the release of free $\beta \gamma$ subunits (Neptune and Bourne, 1997). We found that morphine-induced membrane ruffling was observed primarily at the front edges of migrating cells, in which Rac was colocalized (Fig. $1 \mathrm{Ab}, \mathrm{Bf}$ ). Because Rac activation is known to be a downstream signal of PI3K $\gamma$ (Hall, 1998; Li et al., 2000), the 


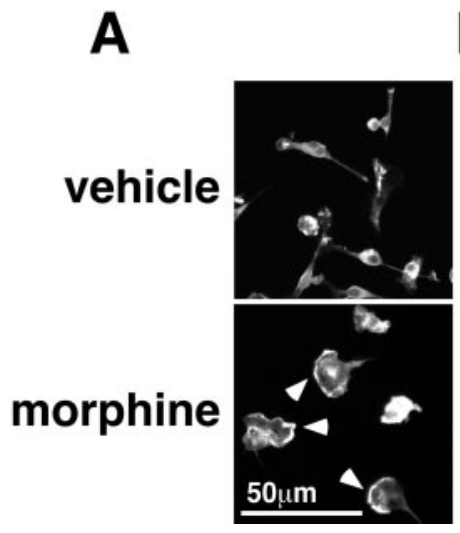

B
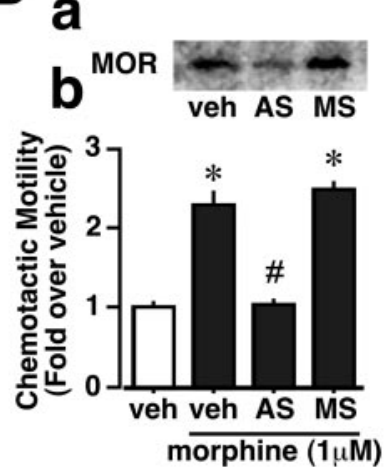

Figure 3. Blockade of morphine-induced EOC 2 cell chemotaxis by treatment with AS-ODN for MOR. A, Morphine-induced membrane ruffling in EOC 2 cells. The cells were treated with DMEM or morphine $(1 \mu \mathrm{M})$ for 30 min and stained with Texas Red-conjugated phalloidin. The arrowheads point out $\mathrm{F}$-actin in the ruffling region. $B a, \mathrm{MOR}$ knock-down in the EOC 2 cells. Microglia were pretreated with vehicle (veh), AS-ODN (AS), or MS-ODN (MS). Bb, Blockade of morphine-induced chemotaxis in EOC 2 by AS-ODN but not MS-ODN. ${ }^{*} p<0.05$ versus vehicle; ${ }^{\#} p<0.05$ versus morphine alone.

mechanisms underlying morphine-induced chemotaxis appear to include sequential activations of $\mathrm{MOR}, \mathrm{G}_{\mathrm{i} / \mathrm{o}}, \mathrm{PI} 3 \mathrm{~K}$, and Rac.

Such a rapid activation of microglia by morphine seems to contradict a previous report, which found morphine-induced apo- ptosis in microglia (Hu et al., 2002). However, because this weak toxicity was not observed as early as any time points on the first day, it unlikely contradicts the present study, which is focused on morphine-induced activation at $30-60 \mathrm{~min}$. It also appears that there is another previous finding that morphine inhibits chemotaxis toward a variety of stimuli (Chao et al., 1997). However, the pretreatment of microglia with morphine by itself, which causes microglial chemotaxis, might be different from in treatment with both morphine and other chemoattractants.

Another issue in the present study is the finding that the morphine treatment increased BDNF gene transcription. It is well known that BDNF gene expression is regulated by the phosphorylation of CREB (cAMP response element-binding protein), which plays an essential role in the development of morphine dependence (Shaw-Lutchman et al., 2002). This fact is closely related to the current finding that naloxone-precipitated physical dependence was markedly attenuated in conditional $b d n f$ knockout mice (Akbarian et al., 2002). Thus, to characterize the signaling pathways to CREB activation would be a good strategy to study the molecular mechanisms for novel morphine-induced microglial activation in terms of BDNF gene transcription. CREB activation includes three pathways, i.e., cAMP-dependent protein kinase, calcium/calmodulin-dependent kinase, and ERK1/2 (West et al., 2001). Because opioid receptors are well known to mediate the inhibition of adenylyl cyclase, this first pathway is unlikely to be involved. Furthermore, Because BDNF gene ex-

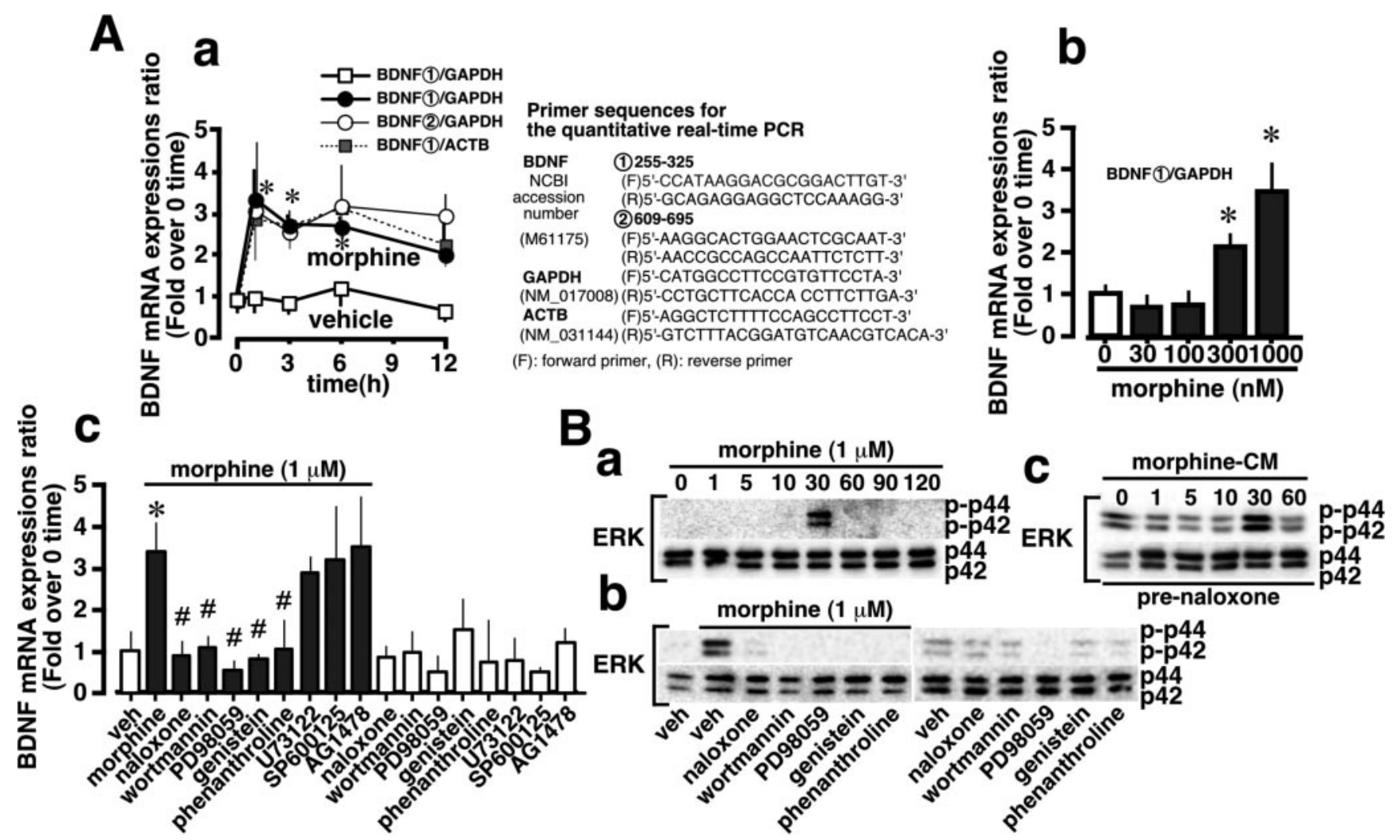

Figure 4. Morphine-induced BDNF mRNA expression in microglia. Aa, The time course of the BDNF mRNA expression induced by $1 \mu \mathrm{m}$ morphine. Primer sequences for two sets of BDNF, GAPDH, and ACTB in experiments for the time course study. Ab, Morphine-stimulated BDNF mRNA expression in a concentration-dependent manner at $1 \mathrm{hr}(0-1 \mu \mathrm{M}) . A c$, Effects of various inhibitors. Cells were pretreated with vehicle (veh; DMEM), $1 \mu$ m naloxone, $1 \mu \mathrm{m}$ wortmannin, $1 \mu \mathrm{M}$ PD98059, $3 \mu \mathrm{m}$ genistein, $300 \mu \mathrm{m}$ 1,10-phenanthroline, $1 \mu \mathrm{m}$ U73122, $1 \mu \mathrm{m}$ SP600125, and $3 \mu \mathrm{m}$ AG1478 for 30 min before the addition of 1 $\mu \mathrm{m}$ morphine for $1 \mathrm{hr}$. After treatments with morphine and inhibitors, microglial BDNF mRNA expression was measured by a real-time PCR method. Data show the mean \pm SEM from four to six independent experiments. $B$, Effects of various inhibitors on morphine-induced phosphorylation of ERK1/2 in microglia. Cell lysates were subjected to Western blotting with anti-ERK1/2 and anti-phospho-ERK1/2 antibodies. $B a$, Time course. $B b$, Effects of various inhibitors on morphine-induced phosphorylation of the ERK1/2 at $30 \mathrm{~min}$. $B c$, The phosphorylation of ERK1/2 by CM prepared from morphine-stimulated culture in the presence of naloxone. All results were reproducible in another set of experiments. The $\mathrm{IC}_{50}$ values were as follows: naloxone, $45.06 \pm 13.67 \mathrm{~nm}$; wortmannin, $73.62 \pm 10.13 \mathrm{~nm}$; PD98059, $122.20 \pm 9.27$ nм; genistein, $1.06 \pm 0.079 \mu \mathrm{m}$; and 1,10-phenanthroline, $36.34 \pm 20.82 \mu \mathrm{m} .{ }^{*} p<0.05$ versus vehicle; ${ }^{*} p<0.05$ versus morphine alone. 
pression was not affected by U73122, an inhibitor of phospholipase C, the calcium-mediated calmodulin-dependent kinase pathway is also unlikely. Indeed, we could not detect any calcium mobilization by $10-100 \mu \mathrm{M}$ morphine in cultured microglia (data not shown). On the other hand, BDNF gene expression was abolished by naloxone, wortmannin, and PD98059. These results suggest that morphine-induced enhancement of BDNF gene expression is mediated through activation of ERK1/2. Indeed, the pharmacological profiles of various inhibitors of BDNF gene expression and ERK1/2 phosphorylation are quite similar (Fig. $4 A c, B b)$. However, the significantly increased phosphorylation of ERK1/2 by morphine was only observed as late as $30 \mathrm{~min}$, being in contrast with many other cases, in which the phosphorylation that occurs through GPCRs (G-protein-coupled receptors) or growth factor receptors takes place within the first several minutes (Schmidt et al., 2000).

Therefore, alternative, indirect pathways for morphineinduced ERK1/2 phosphorylation are likely involved. Indeed, the CM prepared from morphine-treated microglia also increased the ERK1/2 phosphorylation only at $30 \mathrm{~min}$ in the presence of naloxone (Fig. $4 B c$ ). These findings suggest that certain other factors secreted from morphine-treated microglia are responsible for this indirect activation of ERK1/2. This view is supported by the findings that both BDNF gene expression and ERK1/2 phosphorylation were significantly inhibited by genistein, a tyrosine kinase inhibitor, and 1,10-phenanthroline, a matrix metalloprotease inhibitor. The metalloproteases are involved in the shedding of endogenously expressed growth factor-like ligands, such as the EGF-like ligands, from their plasma membrane anchor (Wetzker and Bohmer, 2003). The current study demonstrates that morphine stimulation activates metalloproteases to generate EGF-like growth factors in human embryonic kidney 293 cells overexpressed with MOR (Belcheva et al., 2001). All of these results suggest that unknown AG1478 (an EGFR tyrosine kinase inhibitor)-insensitive growth factors, generated through metalloproteases activated by MOR signaling, might be involved in the activation of ERK1/2 and the enhanced BDNF gene expression. Although the mechanisms for the late and short-lived ERK1/2 phosphorylation remain under investigation, the mechanisms for the counteracting CM factors, e.g., by an inhibition of phosphorylation or attributable to the low expression of the putative growth factor receptors, must for the moment be subjects for the future. However, the morphine-induced membrane ruffling is unlikely to be mediated by CM factors, because it was not affected by genistein or 1,10-phenanthroline. Because the membrane ruffling and chemotaxis as well as the ERK1/2 phosphorylation were abolished by wortmannin, direct PI3K activation (Lopez-Ilasaca et al., 1997), without any activity of CM factors, could also have caused the ERK1/2 phosphorylation, even in the presence of 1,10phenanthroline and genistein. Although many possibilities are worthy of consideration, this argument might be solved in part by the current finding that the PI3K species (PI3K $\gamma$, Class IB) that preferentially activates Rac is different from the PI3K (Class IA) that activates Ras, an upstream molecule of ERK1/2 (Wennstrom and Downward, 1999; Wymann et al., 2003).

Finally, we observed that relatively higher concentrations $(0.3-1 \mu \mathrm{M})$ of morphine caused microglial activation in terms of chemotaxis and BDNF gene expression. Recent evidence has suggested that chronic and high-dose morphine activates spinal and cortical astrocytes, and these changes as well as morphine tolerance are blocked by glial inhibitors (Song and Zhao, 2001; Raghavendra et al., 2002). These findings many provide a new aspect of the molecular basis of mechanisms for morphine toler- ance and dependence through neuron-glia (astrocyte and microglia) interactions.

In conclusion, the present study demonstrates that morphine causes membrane ruffling, chemotaxis, and enhanced BDNF gene expression in microglia. The latter effect appeared to be mediated by CM growth factors generated through morphineinduced activation of metalloproteases.

\section{References}

Akbarian S, Rios M, Liu RJ, Gold SJ, Fong HF, Zeiler S, Coppola V, Tessarollo L, Jones KR, Nestler EJ, Aghajanian GK, Jaenisch R (2002) Brainderived neurotrophic factor is essential for opiate-induced plasticity of noradrenergic neurons. J Neurosci 22:4153-4162.

Bal-Price A, Brown GC (2001) Inflammatory neurodegeneration mediated by nitric oxide from activated glia-inhibiting neuronal respiration, causing glutamate release and excitotoxicity. J Neurosci 21:6480-6491.

Belcheva MM, Szucs M, Wang D, Sadee W, Coscia CJ (2001) mu-Opioid receptor-mediated ERK activation involves calmodulin-dependent epidermal growth factor receptor transactivation. J Biol Chem 276:33847-33853.

Calvo CF, Cesselin F, Gelman M, Glowinski J (2000) Identification of an opioid peptide secreted by rat embryonic mixed brain cells as a promoter of macrophage migration. Eur J Neurosci 12:2676-2684.

Chao CC, Hu S, Shark KB, Sheng WS, Gekker G, Peterson PK (1997) Activation of mu opioid receptors inhibits microglial cell chemotaxis. J Pharmacol Exp Ther 281:998-1004.

Cotrina ML, Lin JH, Lopez-Garcia JC, Naus CC, Nedergaard M (2000) ATP-mediated glia signaling. J Neurosci 20:2835-2844.

Fields RD, Stevens-Graham B (2000) ATP: an extracellular signaling molecule between neurons and glia. Trends Neurosci 23:625-633.

Fields RD, Stevens-Graham B (2002) New insights into neuron-glia communication. Science 298:556-562.

Hall A (1998) Rho GTPases and the actin cytoskeleton. Science 279:509-514.

Hamabe W, Fujita R, Ueda H (2003) Neuronal nectosis inhibition by insulin through protein kinase $\mathrm{C}$ activation. J Pharmacol Exp Ther 307:205-212.

Hansson E, Ronnback L (2003) Glial neuronal signaling in the central nervous system. FASEB J 17:341-348.

Honda S, Sasaki Y, Ohsawa K, Imai Y, Nakamura Y, Inoue K, Kohsaka S (2001) Extracellular ATP or ADP induce chemotaxis of cultured microglia through $\mathrm{G}_{\mathrm{i} / \mathrm{o}}$-coupled P2Y receptors. J Neurosci 21:1975-1982.

$\mathrm{Hu}$ S, Sheng WS, Lokensgard JR, Peterson PK (2002) Morphine induces apoptosis of human microglia and neurons. Neuropharmacology 42:829-836.

Inoue M, Mishina M, Ueda $H$ (2003) Locus-specific rescue of GluR $\epsilon 1$ NMDA receptors in mutant mice identifies the brain regions important for morphine tolerance and dependence. J Neurosci 23:6529-6536.

Lauffenburger DA, Horwitz AF (1996) Cell migration: a physically in tegrated molecular process. Cell 84:359-369.

Li Z, Jiang H, Xie W, Zhang Z, Smrcka AV, Wu D (2000) Roles of PLC- $\beta 2$ and $\beta 3$ and PI $3 K \gamma$ in chemoattractant-mediated signal transduction. Science 287:1046-1049.

Lopez-Ilasaca M, Crespo P, Pellici PG, Gutkind JS, Wetzker R (1997) Linkage of $\mathrm{G}$ protein-coupled receptors to the MAPK signaling pathway through PI 3-kinase gamma. Science 275:394-397.

Mao J, Sung B, Ji RR, Lim G (2002) Chronic morphine induces downregulation of spinal glutamate transporters: implications in morphine tolerance and abnormal pain sensitivity. J Neurosci 22:8312-8323.

Neptune ER, Bourne HR (1997) Receptors induce chemotaxis by releasing the betagamma subunit of Gi, not by activating Gq or Gs. Proc Natl Acad Sci USA 94:14489-14494.

Olivas E, Chen BB, Walker WS (1995) Use of the Pannell-Milstein roller bottle apparatus to produce high concentrations of CSF-1, the mouse macrophage growth factor. J Immunol Methods 182:73-79.

Poo MM (2001) Neurotrophins as synaptic modulators. Nat Rev Neurosci 2:24-32.

Raghavendra V, Rutkowski MD, DeLeo JA (2002) The role of spinal neuroimmune activation in morphine tolerance/hyperalgesia in neuropathic and sham-operated rats. J Neurosci 22:9980-9989.

Ruzicka BB, Fox CA, Thompson RC, Meng F, Watson SJ, Akil H (1995) Primary astroglial cultures derived from several rat brain regions differentially express mu, delta and kappa opioid receptor mRNA. Brain Res Mol Brain Res 34:209-220. 
Schmidt H, Schulz S, Klutzny M, Koch T, Handel M, Hollt V (2000) Involvement of mitogen-activated protein kinase in agonist-induced phosphorylation of the mu-opioid receptor in HEK 293 cells. J Neurochem 74:414-422.

Shaw-Lutchman TZ, Barrot M, Wallace T, Gilden L, Zachariou V, Impey S, Duman RS, Storm D, Nestler EJ (2002) Regional and cellular mapping of cAMP response element-mediated transcription during naltrexoneprecipitated morphine withdrawal. J Neurosci 22:3663-3672.

Song P, Zhao ZQ (2001) The involvement of glial cells in the development of morphine tolerance. Neurosci Res 39:281-286.

Ueda H, Inoue M, Takeshima H, Iwasawa Y (2000) Enhanced spinal nociception receptor expression develops morphine tolerance and dependence. J Neurosci 20:7640-7647.

Ueda H, Inoue M, Mizuno K (2003) New approaches to study the development of morphine tolerance and dependence. Life Sci 7 4:313-320.
Wennstrom S, Downward J (1999) Role of phosphoinositide 3-kinase in activation of ras and mitogen-activated protein kinase by epidermal growth factor. Mol Cell Biol 19:4279-4288.

West AE, Chen WG, Dalva MB, Dolmetsch RE, Kornhauser JM, Shaywitz AJ, Takasu MA, Tao X, Greenberg ME (2001) Calcium regulation of neuronal gene expression. Proc Natl Acad Sci USA 98:11024-11031.

Wetzker R, Bohmer FD (2003) Transactivation joins multiple tracks to the ERK/MAPK cascade. Nat Rev 4:651-657.

Williams JT, Christie M, Manzoni O (2001) Cellular and synaptic adaptations mediating opioid dependence. Physiol Rev 81:299-343.

Wymann MP, Zvelebil M, Laffargue M (2003) Phosphoinositide 3-kinase signaling - which way to target? Trends Pharmacol Sci 24:366-376.

Yokomizo T, Izumi T, Chang K, Takuwa Y, Shimizu T (1997) A G-proteincoupled receptor for leukotriene B4 that mediates chemotaxis. Nature 387:620-624. 